\title{
MULTIVARIATE STATISTICS OF SECURITY PERCEPTIONS IN EUROPE
}

\author{
Daniela LIEBERZ
}

\begin{abstract}
A range of methods were applied to evaluate and understand security perceptions across five European countries. Eight dimensions of the security perception were assessed, namely physical safety, territorial integrity, environmental and ecological security, cultural identity, social stability, political stability, economic prosperity, and information and cyber security. Their evaluation and prioritisation was performed using the Perception Security Matrix representation. Statistical methods - contingency tables, functional analysis and structural equation modelling - were applied to explain the relationships between the dimensions and their dependencies on risk categories. Three basic principles were derived: "freedom from want" related to economic and environmental conditions, "freedom from instability" as determined by social and political issues, and "freedom from fear," meaning freedom from war, terrorism and aggressiveness, and related also to the integrity of the private sphere. These general principles manifest themselves differently in different countries determined by specific political, social, cultural, and economic context.
\end{abstract}

Keywords: Perception of security, risks, political level, desk research, political instability, social instability, Structural Equation Modelling, statistical analysis, comparative analysis, European states, political actors.

\section{Introduction}

Human Security is turning into an essential aspect of human development. The respective concept was introduced in the 1994 global Human Development Report (HDR). ${ }^{1}$ It is based on three basic principles: Freedom from Fear, Freedom from Want and Freedom to Live in Dignity. That means security refers not only to the absence of dangers, but also to the subjective perception of potential dangers. Hans Günter Brauch mentioned that "the perception of security dangers depends on the world views or traditions of the analyst and of the mind-set of the policy makers."2 In this regard, it was stated ${ }^{3}$ that the notion of security culture ${ }^{4}$ can be applied at two levels of analysis:

- the citizen level, where the human being is the referent; and 
- the government level (national security) with the state as the referent.

At the level of the individual citizen, security is measured with regard to her or his economic, food, environment or health situation, whereas at a governmental level, political, social and cultural aspects take precedence. The HDR listed the following dimensions of human security: Economic, Health, Personal, Political, Food, Environmental, and Community. Brauch defines the following dimensions of human security: political-military vulnerabilities, economic vulnerabilities, environmental challenges, political instabilities, societal instabilities. ${ }^{5}$ For Fabien Nathan ${ }^{6}$ these include: physical weakness, legal, organized, technical, political, socio-economic, psychological, and cultural vulnerabilities. ${ }^{7}$

These examples demonstrate that there is no definitive comprehensive list of security dimensions. One reason is that Human Security is a rather "flexible approach" that depends on context, as stated by O.A. Gomez. ${ }^{8}$ People's security perceptions are dependent on their historical, cultural and educational backgrounds as well as social and geographic conditions, and thus differ widely.

This diversity of security perceptions presents a challenge to international bodies such as the European Union as it tries to develop common security policies for all of its member states and their citizens. Given this challenge, the project "Evolving Concepts of Security" (EvoCS) ${ }^{9}$ was launched in June 2014 as part of the Seventh Framework Programme. The goal of the project is to identify and understand current security concerns in a range of European regions and countries.

Based on the data collected by EvoCS, this paper aims to understand the factors contributing to security concerns and to compare them among European countries. It also explores the question if common basic principles underlie all these concerns.

Our empirical analysis draws upon instruments from Risk Management (RM) to Security Perception Management (SPM) to develop a probability and impact diagram, which is used to evaluate and prioritise the values of concern. Then, we perform statistical analysis in order to understand the main influence factors and relationships between the assessed dimensions of security perception. The analysis was performed with the SPSS statistical tool by using descriptive statistics, contingency table analyses and multivariate analyses like Factor Analysis (FA), Linear Regressions (LR) and Structural Equation Modelling (SEM).

This study is not part of the EvoCS itself; it is an additional work based on the data collected in the project. The paper is structured as follows. The first section gives detailed information about the data employed in this analysis, the context and assessment of security dimensions. The second section presents the results of the descriptive statistics, the third shows the method and results of the assessment map 
(SPM) and the fourth provides the results of multivariate methods. The last section contains a discussion on the results and concluding remarks.

\section{Description of Data}

The EvoCS project seeks to study the variability of perceived security by taking into account different factors:

- Countries

- Sources

- Information from reports

- Security dimensions

- Political levels

○ Actors

○ Security challenges

\section{Countries}

Although 12 European states grouped into four regions participated in the project, data from only five states across the regions were available for this analysis:

\begin{tabular}{l|l}
\hline Country & Region \\
\hline Spain & West-Mediterranean EU \\
Poland & Eastern EU-Border \\
United Kingdom, Netherlands & North-Western EU \\
Serbia & South-Eastern EU \\
\hline
\end{tabular}

In the following we use the short notation UK for the United Kingdom and NL for The Netherlands.

\section{Sources}

The collection of data is based on desk research, interviews and workshops revealing direct information about who are affected by what problem and to what extent. Regional case study teams working in the EvoCS project used the same approach to systematically elicit concepts of security from different sources: Government, Parliament, Academia, Media, Private sector, and NGOs.

Publications from only the last 10 years were considered. 


\section{Information from reports (see Table 1)}

The information of each report is analysed and parameterised through a group of variables, which were defined conceptually in advance.

\section{Core values}

The core value variables are, as the name already indicates, the central variables of the analysis. Core values refer to the different aspects of life that actors seek to make secure: "physical safety," "territorial integrity," "environmental and ecological security," "cultural identity," "social stability," "political stability," "economic prosperity," and "information and cyber security." Upon the analysis of the respective source, they can be defined as "Main Topic" (value 3), "Mentioned" (value 1) or "Absent" (value 0). In a similar way, the variables describing political level were assessed. The varying degree of salience for each core value is of crucial importance in comparing the prevalent concept of security in different countries.

\section{Actors}

The nature of security concepts is directly related to the political actors. It is essential to understand how different political actors across Europe prioritise different core values and perceive different risks, how they address these values at different levels. In the analysed security discourses, multiple actors use claims and actions such as statements and speeches to contribute to shared understandings of what security is. In order to get all the nuances of activities of political actors, eleven variables describing actors were defined: National government, National parliament, European Union, International institution, Foreign government, Civil society, Private sector, Academia, Media, General public, and Policy institutes.

Table 1 shows the values they can get. Each variable describing an actor can be assessed as:

- "Addressor" - this is the actor who raises the problem, who expresses itself explicitly on a given security issue;

- "Addressee" is the actor to whom the statement of the "Addressor" is directed (the actor who should find solution);

- "Addressee and Addressor" or "Affected" is an actor with both functions;

- "Object" is an actor who is impacted by the security problem in relation to a given core value (e.g. victims).

- "Absent" - the actor was not involved in the debate.

The actor who may affect a core value creating insecurity perception is described via a textbox field named "Subject" for a concise recording of this actor. 
Table 1. Dimensions of the security perception (EvoCS Project).

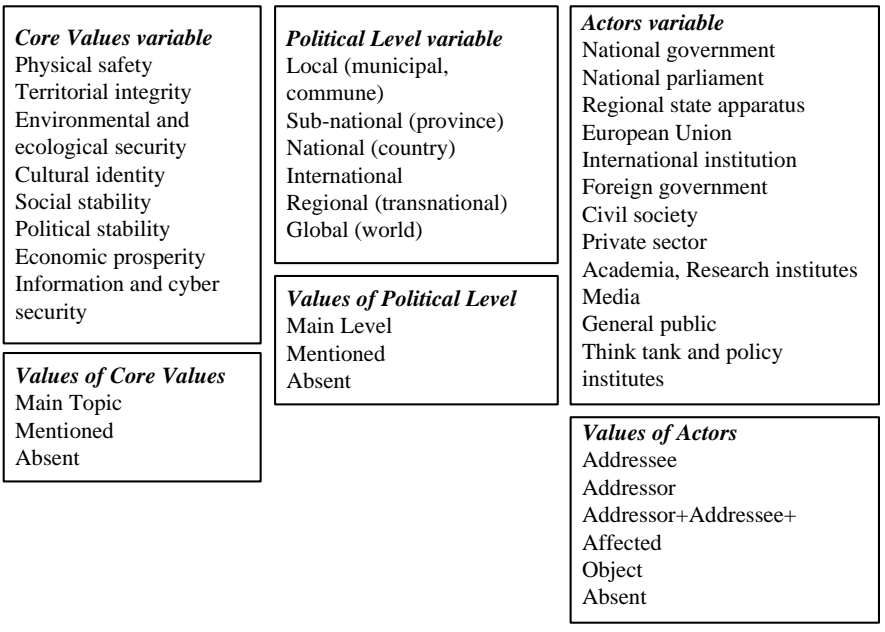

Risk Categories variable

Political or religious conflicts

Corruption

Organized crime / Terrorism

Violence, Violence on women

and children

Economic recession

Illegal traffic

Discrimination

Global risks

Natural risks

Man-made risks

Technical risks, Cyber-attack,

Data security

Security culture

Critical infrastructure

Immigration, Refugees

Space research security

Other

Values of Risk Categories

Yes

No

\section{Political level}

Political actors take action in different spaces, locations, audience structure, levels at which they call for action to be taken. These levels might be different for different actors. Five variables describe the political level of discussions: Local, Subnational, National, International, Transnational/Regional, and Global.

\section{Security Challenges}

Any phenomenon that is qualified as a threat, hazard or risk is explained in a free text variable called "security challenge." This field is afterward discretised into a set of dichotomic risk categories ( $y e s=1, n o=0$ ).

For the analysis, it is important to note that each report can assess more than one actor, more than one political level, and most importantly - more than one security dimension (core value). From a statistical point of view each report represents one case study.

\section{Results of Descriptive Statistic}

Using the statistical tool SPSS we first performed a descriptive analysis of the whole sample and for each country-related data set. This kind of analysis allows for a comparison among different countries and sources regarding core values, political levels and actors. A deeper understanding is reached by including the description of the "security challenges." The number of reports per country varies: NL (539), UK (430), Serbia (336), Spain (323), and Poland (201). 


\section{Sources of reports}

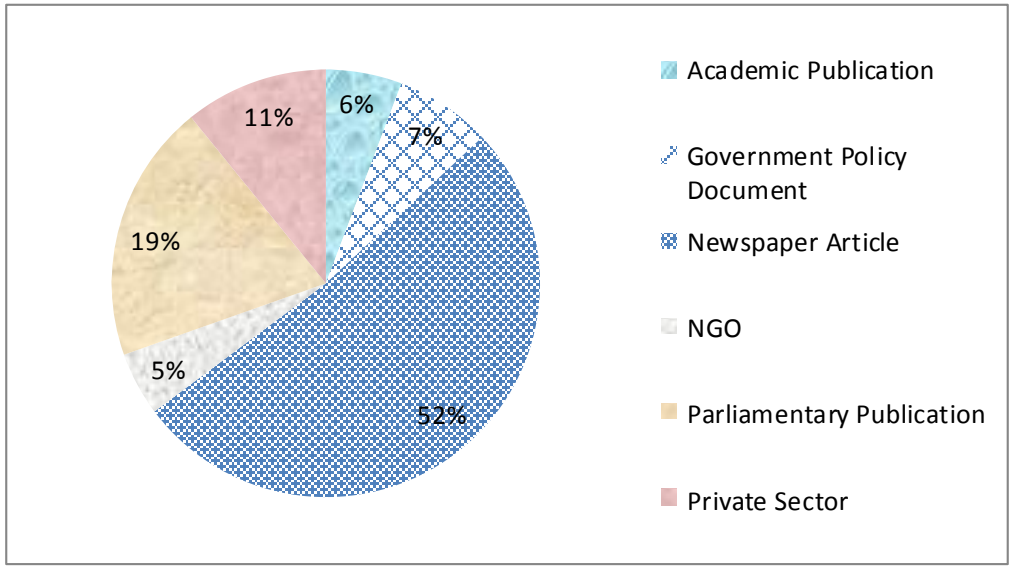

Figure 1: Distribution of the issues/reports over the sources.

Overall, most of the reports were acquired from newspapers $(52 \%)$; together, the governmental and parliament reports represented $27 \%$ of the sample, and the rest of the sources contributed $21 \%$. This distribution is quite similar among all countries. One minor difference is that the "private sector" contributions are more common in the UK and the NL, which implies that the private sector is more involved in security discussions in these two countries compared to others.

We decided to see if the source category "newspaper" shows a special distribution compared to the rest. It seems that the "physical safety" is of most concern for both groups, but its fraction in the newspaper group is higher than in the non-newspaper group (Figure 2, left). Consequently, the other security dimensions are more salient in the "non-newspaper" group, particularly the "economic prosperity." We also found that for the "private sector" the aspect of "economic prosperity" is the biggest concern (Figure 2, right) - in $43 \%$ of the reports from the private sector the "economic prosperity" was assessed as "Main Topic."

\section{Core Values}

The percentages in table 2 show how often each core value was assessed as "Main Topic" related to the total number of reports in each country. For example, "physical safety" was of highest concern for $66 \%$ of the reports from Serbia whereas "cultural integrity" was of highest concern just for $6 \%$. The sums on the columns do not amount 100 percent because each report can address more than one core value, as specified before. Moreover, the sums can also be lower than 100 percent because 


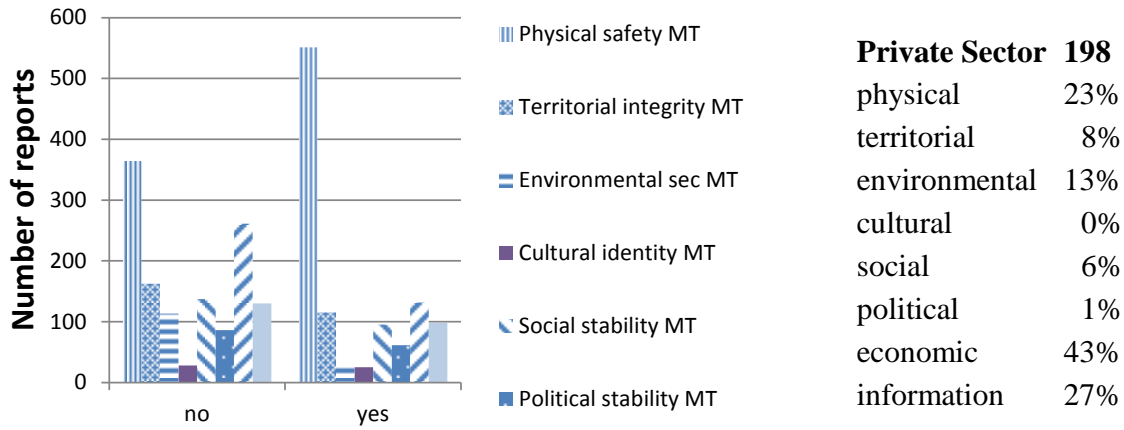

Newspaper reports

Figure 2. Left: number of reports with "Main Topic" (MT) specified core values displayed over the two source categories "newspaper" or "non-newspaper"; Right: the percentage of the core values specified as "Main Topic" in private sector reports.

there are reports where no core value could be assigned as "Main Topic." This characteristic also applies to the analysis of political levels.

The most assessed "Main Topic" for all countries was "physical safety," followed by the "economic prosperity" (see Figure 3). The concern of "territorial integrity" is higher for Poland and of "social stability" - for Serbia. The "cultural identity" was not a source of concern; it will be shown that it often accompanies other major concerns. "Information security" is the "Main Topic" in approximately $12 \%$ of the reports (see Table 2).

Table 2. Core values assessed with "Main Topic" distributed over the countries in percent related to the number of issues of each country.

\begin{tabular}{l|cccccc}
\hline Core Value & Netherlands & Poland & Serbia & Spain & UK & Total \\
\hline Physical safety & $40,3 \%$ & $35,8 \%$ & $66,4 \%$ & $59,4 \%$ & $49,1 \%$ & $50,0 \%$ \\
Territorial integrity & $15,6 \%$ & $23,9 \%$ & $14,3 \%$ & $11,1 \%$ & $14,2 \%$ & $15,1 \%$ \\
Environmental security & $5,2 \%$ & $5,5 \%$ & $7,1 \%$ & $9,0 \%$ & $11,2 \%$ & $7,7 \%$ \\
Cultural identity & $0,6 \%$ & $1,0 \%$ & $3,6 \%$ & $6,2 \%$ & $3,7 \%$ & $2,9 \%$ \\
Social stability & $15,2 \%$ & $10,9 \%$ & $19,0 \%$ & $11,1 \%$ & $6,5 \%$ & $12,7 \%$ \\
Political stability & $5,0 \%$ & $12,9 \%$ & $9,2 \%$ & $6,8 \%$ & $9,5 \%$ & $8,0 \%$ \\
Economic prosperity & $12,8 \%$ & $22,4 \%$ & $33,0 \%$ & $25,7 \%$ & $19,5 \%$ & $21,4 \%$ \\
Information security & $10 \%$ & $12 \%$ & $12 \%$ & $11 \%$ & $18 \%$ & $13 \%$ \\
\hline
\end{tabular}




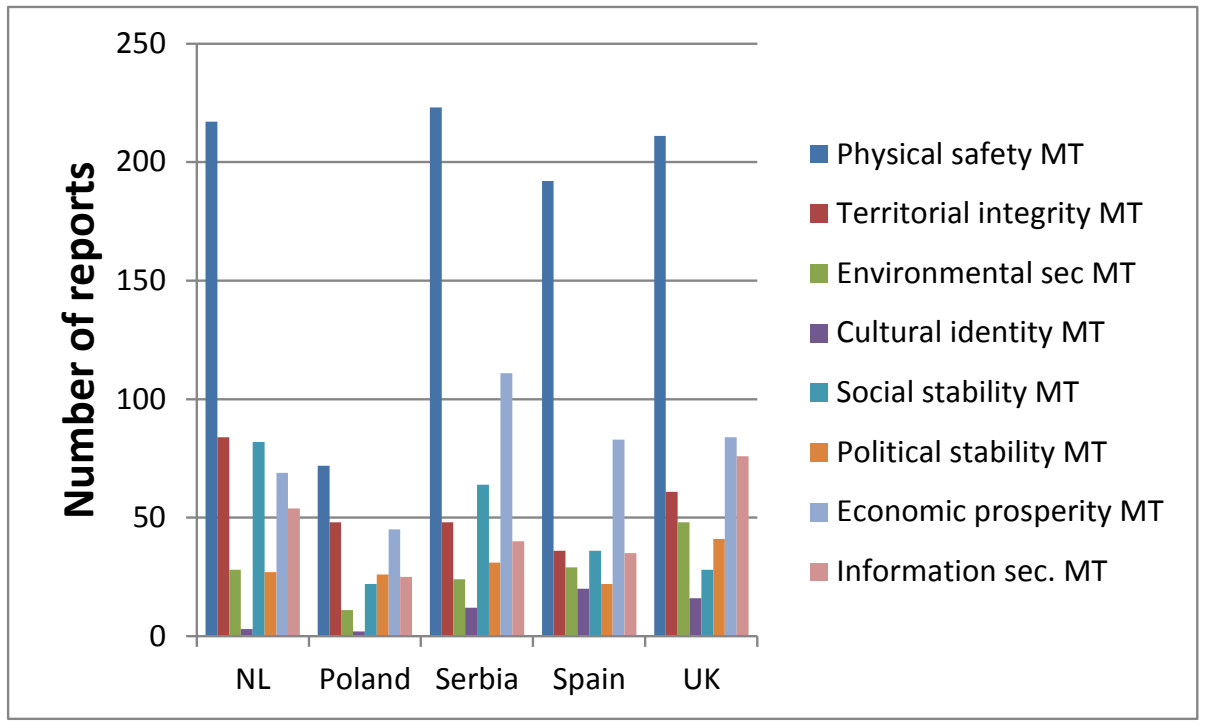

Figure 3: Distribution of the "Main Topic" (MT) assessments of core values over the countries.

Generally, there are no big differences among the countries in the relative assessment of the security core values.

\section{Regional comparison}

UK and NL belong to the North-Western region and their combined samples accounts for $50 \%$ of the total sample size. We compared the frequency of core variables between the North-Western region and the rest. "Physical safety" and "economic prosperity" were significantly less weighted in this region $(\mathrm{P}<0,0005)$.

The estimations of core values for Spain, Serbia and Poland were also compared. The results show that "social stability" and "physical safety" are of high salience for Serbia and Spain, and that "territorial integrity" is important for Poland.

\section{Political levels}

The debate on human security was mostly performed at the national political level (see Figure 4). The regional and global levels are infrequent. It is also evident that newspapers refer to the local level of security concerns (blue bar). Differences between countries can be seen in table 3 .

In addition to the national-level, in Serbia and Poland the local political level is quite important as well. Poland also expresses security concerns at international and regional level. 


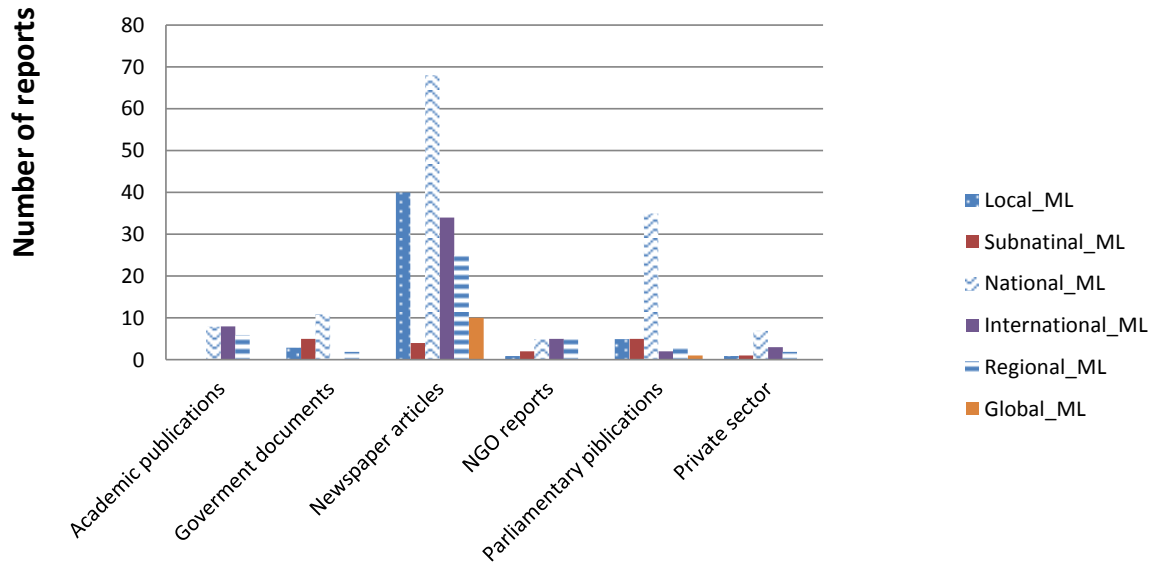

Figure 4: Distribution of the number of reports where the various political levels were assessed as "Main Level" (ML) over the source types.

Table 3. Political levels of perceived security values across the countries.

\begin{tabular}{l|cccccc}
\hline $\begin{array}{l}\text { Political } \\
\text { Main Level }\end{array}$ & Netherlands & Serbia & Spain & $\begin{array}{c}\text { United } \\
\text { Kingdom }\end{array}$ & Poland & Total \\
\hline Local & $14 \%$ & $26 \%$ & $13 \%$ & $6 \%$ & $25 \%$ & $15 \%$ \\
Subnational & $4 \%$ & $14 \%$ & $18 \%$ & $13 \%$ & $8 \%$ & $11 \%$ \\
National & $60 \%$ & $70 \%$ & $63 \%$ & $69 \%$ & $67 \%$ & $65 \%$ \\
International & $14 \%$ & $9 \%$ & $9 \%$ & $14 \%$ & $26 \%$ & $13 \%$ \\
Regional & $3 \%$ & $13 \%$ & $6 \%$ & $5 \%$ & $21 \%$ & $8 \%$ \\
Global & $1 \%$ & $5 \%$ & $11 \%$ & $2 \%$ & $5 \%$ & $4 \%$ \\
\hline
\end{tabular}

\section{Actors}

We have 11 categories of actors; each of them portrayed as having different possible roles (see Table 1). In order to get statistical power we concatenated the roles and only made distinctions between AAA (Addressor/Addressee/Affected) and Object (e.g. victim). Table 4 shows for the whole sample in the very right columns how often the correspondent actor was perceived, and in the left columns how the assessment of his role was balanced between AAA and Object. The actors most often per- 
Table 4. Assessment of roles for different categories of actors.

\begin{tabular}{l|cccc}
\hline Actors & $\boldsymbol{A}+\boldsymbol{A}+\boldsymbol{A}$ & Object & Total perceived & Absent \\
\hline National Government & $88 \%$ & $12 \%$ & $74 \%$ & $26 \%$ \\
National Parliament & $97 \%$ & $3 \%$ & $33 \%$ & $67 \%$ \\
Regional State Apparatus & $77 \%$ & $23 \%$ & $24 \%$ & $76 \%$ \\
European Union & $74 \%$ & $26 \%$ & $17 \%$ & $83 \%$ \\
International Institution & $78 \%$ & $22 \%$ & $15 \%$ & $85 \%$ \\
Foreign Government & $60 \%$ & $40 \%$ & $20 \%$ & $80 \%$ \\
Civil Society & $64 \%$ & $37 \%$ & $31 \%$ & $69 \%$ \\
Private Sector & $64 \%$ & $36 \%$ & $42 \%$ & $58 \%$ \\
Academia and research institutes & $90 \%$ & $10 \%$ & $15 \%$ & $85 \%$ \\
Media & $93 \%$ & $7 \%$ & $24 \%$ & $76 \%$ \\
General public or individual citizens & $37 \%$ & $63 \%$ & $73 \%$ & $27 \%$ \\
Think tanks and policy institutes & $97 \%$ & $3 \%$ & $28 \%$ & $72 \%$ \\
\hline
\end{tabular}

ceived were the "National government" and the "General public." The "National government" was identified as main actor in $74 \%$ of reports, and from these in $88 \%$ was seen in the AAA role. The "General public" was identified in $73 \%$ of reports, and in $63 \%$ of these it was assessed as Object. The "Private sector" and the "Civil society" show in $42 \%$ and $31 \%$ of the cases, with a similar distribution among the two roles: $64 \%$ (AAA) and 36\% (Object).

Looking at Table 5, it seems that for Poland the "General public" is perceived as having a surprisingly active role and not as Object. This could be an error in the received data and needs to be checked in further studies.

\section{Perceived Risks}

The information on risks/hazards/threats/vulnerabilities is extracted from a text field which we quantified in a number or risk categories. In the following, we show which of these categories were mostly addressed, and afterwards make additional comments on the specificity of each country, as extracted from the text field.

Figure 5 shows the distribution of challenges over the risk categories. There are some categories that were frequently assessed, especially those on the left side of the xaxis. The last ones are special categories of risks assessed in only one (or two) countries. The most sources of concern are:

- Political/religious conflicts;

- Organised crime/terrorism; 
Table 5. Assessments of roles AAA or Object for two actors: "National government" and "General public" in comparison between countries.

\begin{tabular}{|c|c|c|c|c|}
\hline & Actors and Roles & $\begin{array}{c}\text { Addressor or } \\
\text { Addressee }\end{array}$ & Object & $\begin{array}{l}\% \text { from } \\
\text { sample }\end{array}$ \\
\hline Poland & National government & $95 \%$ & $5 \%$ & $75 \%$ \\
\hline 201 cases & General Public & $\underline{88 \%}$ & $12 \%$ & $82 \%$ \\
\hline Serbia & National government & $96 \%$ & $4 \%$ & $71 \%$ \\
\hline 336 cases & General Public & $33 \%$ & $67 \%$ & $87 \%$ \\
\hline Spain & National government & $95 \%$ & $5 \%$ & $82 \%$ \\
\hline 323 cases & General Public & $23 \%$ & $77 \%$ & $78 \%$ \\
\hline NL & National government & $88 \%$ & $12 \%$ & $71 \%$ \\
\hline 539 cases & General Public & $30 \%$ & $70 \%$ & $47 \%$ \\
\hline UK & National government & $61 \%$ & $38 \%$ & $52 \%$ \\
\hline 430 cases & General Public & $6 \%$ & $94 \%$ & $60 \%$ \\
\hline
\end{tabular}

- Economic recession/background;

- Cybersecurity;

- Security culture.

\section{Number of reports}
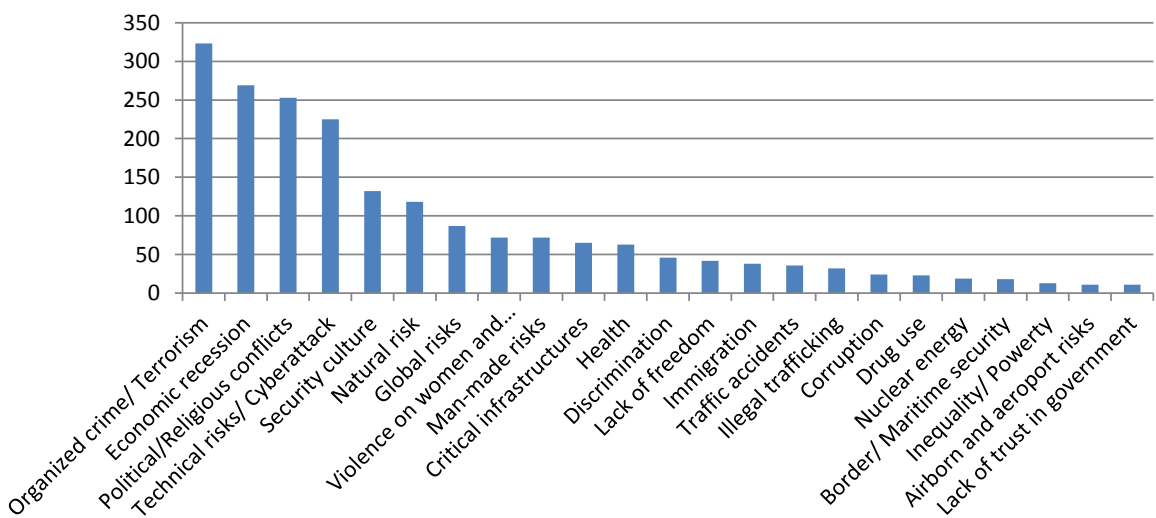

Figure 5: Distribution of reports over the risk categories. 
An insight into the specificity of challenges in different countries is given in Table 6: the most assessed categories are presented (all countries together) in the first column; the other columns show the specific categories additionally assessed in each country.

Even when some categories are salient in all countries, their manifestation may be different depending on the specific politico-social context, as shown in the following discussions.

\section{Discussion: Poland}

Poland shows concerns regarding four main categories of risk: "Political or religious conflicts," "Economic recession," "Traffic accidents," and "Cybersecurity." The fear

Table 6. General and country specific risk categories.

\begin{tabular}{|c|c|c|c|c|c|}
\hline Overall & Netherlands & $U K$ & Serbia & Spain & Poland \\
\hline $\begin{array}{l}\text { Political or } \\
\text { religious } \\
\text { conflicts }\end{array}$ & $\begin{array}{l}\text { Nuclear en- } \\
\text { ergy and } \\
\text { weapons }\end{array}$ & $\begin{array}{l}\text { Immigration } \\
\text { / Refugees }\end{array}$ & $\begin{array}{l}\text { Critical in- } \\
\text { frastructure/ } \\
\text { transport }\end{array}$ & $\begin{array}{l}\text { Immigration/ } \\
\text { Refugees }\end{array}$ & $\begin{array}{l}\text { Traffic acci- } \\
\text { dents }\end{array}$ \\
\hline Corruption & Health & $\begin{array}{l}\text { Space } \\
\text { research }\end{array}$ & $\begin{array}{l}\text { Illegal traf- } \\
\text { fic }\end{array}$ & $\begin{array}{l}\text { Psychological } \\
\text { aggression on } \\
\text { citizens }\end{array}$ & $\begin{array}{l}\text { Exceeding the } \\
\text { authority of } \\
\text { the police }\end{array}$ \\
\hline $\begin{array}{l}\text { Organized } \\
\text { crime, Ter- }\end{array}$ & $\begin{array}{l}\text { Immigration } \\
\text { / Refugees }\end{array}$ & $\begin{array}{l}\text { Maritime } \\
\text { border }\end{array}$ & $\begin{array}{l}\text { Discrimina- } \\
\text { tion }\end{array}$ & $\begin{array}{l}\text { Lack of free- } \\
\text { dom }\end{array}$ & $\begin{array}{l}\text { Security po- } \\
\text { lice threat on }\end{array}$ \\
\hline $\begin{array}{l}\text { Violence, } \\
\text { Violence on } \\
\text { women and } \\
\text { children }\end{array}$ & Violence & $\begin{array}{l}\text { Airborne } \\
\text { and airport } \\
\text { risks }\end{array}$ & $\begin{array}{l}\text { Political or } \\
\text { religious } \\
\text { conflicts }\end{array}$ & \multirow{6}{*}{$\begin{array}{l}\text { Train crash } \\
\text { Demonstra- } \\
\text { tions/ Disobe- } \\
\text { dience } \\
\text { Physical } \\
\text { abuse }\end{array}$} & Food \\
\hline $\begin{array}{l}\text { Economic } \\
\text { recession } \\
\text { Illegal traf- }\end{array}$ & & & & & $\begin{array}{l}\text { Lack of trust } \\
\text { in police, jus- } \\
\text { tice, politics }\end{array}$ \\
\hline fic & & & & & \\
\hline $\begin{array}{l}\text { Discrimi- } \\
\text { nation }\end{array}$ & & & & & \\
\hline Global risks & & & & & \\
\hline $\begin{array}{l}\text { Natural } \\
\text { risks }\end{array}$ & & & & & \\
\hline $\begin{array}{l}\text { Man-made } \\
\text { risks }\end{array}$ & & & & & \\
\hline $\begin{array}{l}\text { Technical } \\
\text { risks, } \\
\text { Cyber-at- } \\
\text { tack, Data } \\
\text { security }\end{array}$ & & & & & \\
\hline
\end{tabular}


of political conflicts is generated partly because of the instability in Ukraine, which is seen as a threat to Poland's security. Military conflicts, aggression, and invasion are possible scenarios involving the political situation in Europe. Strongly related are also the economic concerns, as Russia is a major energy provider. Special risk categories in Poland are the increasing number of road accidents, security of children traveling to school, police abuse of citizen, lack of trust towards politicians, police, and justice. Detailed information about the Polish concerns can be found in the deliverable D6.2 of the EvoCS project "Case Study on the Eastern EU Border.,"10

\section{Discussion: Serbia}

There are four main risk categories depicted in Serbia's reports: "Political/religious conflicts," "Organised crime/terrorism," "Economic recession" and "Cybersecurity." These categories are related to the critical political situation in Serbia, involving the relationships between Russia and Serbia and between Russia and Poland, security problems of Serbs in Kosovo and the existence of Serbian extremists attacking Albanians in Northern Serbia. This situation leads to increased terror activities, violence, aggression and discrimination against Serbs in Kosovo, Roma and the LGBT community. Another effect is the illegal trafficking of drugs and humans, and money laundering. We recommend the deliverable D8.2 of the EvoCS project for detailed information regarding sources of concern in Serbia. ${ }^{11}$

\section{Discussion: Spain}

The data of Spain show increased concerns regarding "Lack of freedom," "Security" in general, "Economic recession," and "Cybersecurity." The statement "lack of freedom" relates to the lack of freedom to express own opinion, to claim justice, and also to the increase in the control of demonstrations. The feeling of insecurity stems from the lack of security for the private sector, lack of job stability, lack of an effective law for social security, lack of investment in the police force, lack of protection for the population, and from physical and mental abuse. Of great concerns are also the increased poverty and social inequality, social exclusion of unemployed young people, and long term unemployment. For more insight into the security concerns for Spain we recommend deliverable D5.2 "Case Study on West Mediterranean EU" of the project EvoCS. ${ }^{12}$

\section{Discussion: Netherlands}

The main concerns in The Netherlands belong to the categories: "Organized crime/ Terrorism" and "Cybersecurity." These manifest at the European level and are not based on internal conflicts. "Political and religious conflicts" was not identified as a source of concern for NL. But various general security aspects in the field of infrastructure security, employees, police, and trust in ministries are communicated. Health and economic aspects are considered to be in need of improving. 


\section{Discussion: UK}

For the United Kingdom, as for The Netherlands, the risk categories ("Organized crime/ Terrorism," "Economic recession" and "Cyber security") are related mainly to the overall political situation in Europe and in the world. International terrorism affecting political security, especially in Northern Ireland, combined with extremism and high level of criminality, are the specifications most often given. Economic aspects are also of big concern in relation to these challenges. Detailed description of concerns for The Netherland and the United Kingdom can be found in the deliverable D7.2 of the EvoCS project, "Case study on North-West Europe."13

\section{Security Perception Assessment Map}

Eight security dimensions (core values) were identified as essential to describe the perception of security at different political levels. In order to estimate and prioritise the salience of these values, taking into account both the intensity and the frequency of perception, we performed a security perception map (SPM) that is analogous to the risk assessment map in Risk Management.

A five-step framework of RM was adapted to the analysis of security perceptions. We can see that the first two steps are already accomplished:

Step 1: Establish context

Step 2: Identify security core values

Step 3: Analyse core values and calculate frequencies and consequence

Step 4: Evaluate and prioritise

Step 5: Mitigation.

In the following we address steps 3 and 4 . In this regard, the assessment of the salience of "core values" for each given country is performed by computing the "frequency" and the "consequence" of each core value. The "Consequence" measures the intensity/impact of the perception: high intensity (3), lower intensity (1). The frequency measures how often such perception occurs. Both dimensions are necessary in order to assess the salience of the core value.

The "frequency" and the "consequence" are calculated as:

$$
\begin{gathered}
\text { Frequency }=\frac{\#(\text { CoreVal }=1)+\#(\text { CoreVal }=3)}{\# I s s u e s} \\
\text { Consequence }=\frac{\#(\text { CoreVal }=1) * 1+\#(\text { CoreVal }=3) * 3}{\#(\text { CoreVal }=1)+\#(\text { CoreVal }=3)}
\end{gathered}
$$


The core values with highest "consequences" and highest "frequencies" indicate the most urgent security aspects to be improved in each specified country. A security perception assessment matrix (SPM) was created. In analogy with RM, the logarithm of the frequencies and consequences were taken. This is necessary because only in this way the "consequence" can be linearly related to the "frequency."

$$
\log (\text { Consequence })=\text { constant }-\log (\text { Frequency })
$$

Figure 6 shows the assessment maps for each country. This representation of core values on the two-dimensional space defined by consequence and frequency enables a comparison of the salience of the core values with each other and between different countries.

It is clear that the "physical safety" (red star) is the most critical value for all countries and the "cultural identity" (black star) is the least critical value. Spain and Ser-
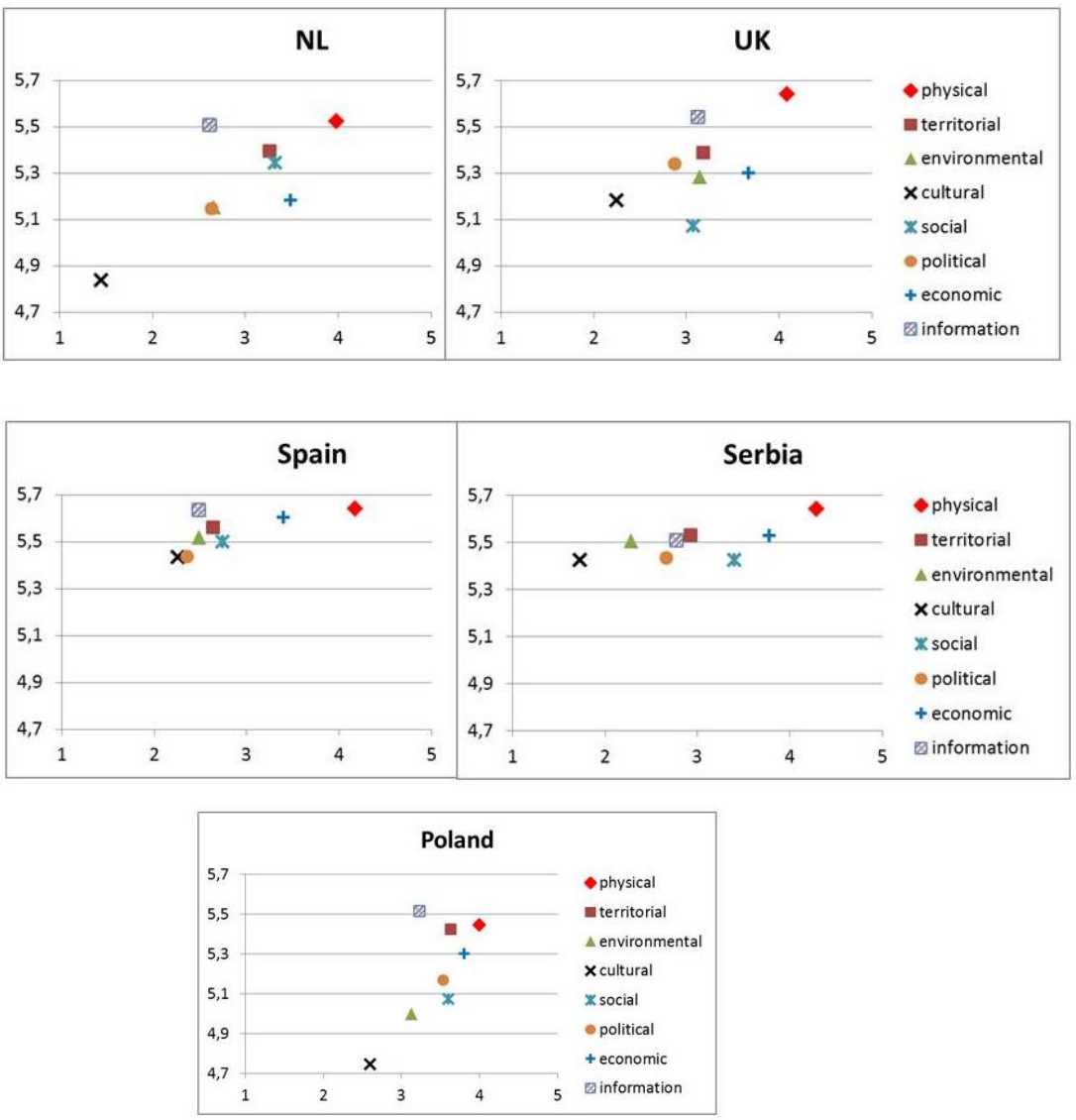

Figure 6: Security values diagrams for all five countries. 
bia are characterized by assessing high salience for almost all core values, whereas the UK, the NL and Poland have low salience for some aspects of security (social, political, cultural and environmental). For Serbia, Spain and Poland, "economic prosperity" in addition to "physical safety" is quite critical. "Territorial integrity" overall has a high position, especially for Poland. Poland's diagram is rather similar to those of UK and NL.

The results of this method are in agreement with those from the descriptive part, but in addition we now have a basis for comparison, which is based upon the interplay of both frequency and intensity of perception.

\section{Multivariate Statistics and Results}

We applied multivariate statistics to investigate relationships between multiple variables trying to understand their interdependencies. One direction of such studies was to examine how the core values relate to the different risk categories, another was to examine if the raise of perception for various core values has a common basis.

\section{Risk Categories as Metrics of perceiving insecurity}

In order to improve our understanding of security perceptions, we analysed which risk categories are related to the various core values. In this way, the risk categories act as metrics for security perception measurement. Therefore, we performed linear regression (LR) analyses with SPSS having the core values as dependent variables and the risk categories as independent factors. The multivariate regressions gave us the main significant influence factors, that were then used as an input for CFA (confirmatory factor analysis) with SEM. More details to SEM and statistical tools are given in an appendix to this paper. As an example, we show the results for "social security" in Figure 7. The hypothesis that it depends on three risk categories (violence/ violence on women and children, immigration, and discrimination) was confirmed by SEM, where the most important factor, i.e. "discrimination" had the biggest weighting factor (1.55). The influence factors for all core values are listed in Table 7 .

This table confirms our expectations. That means, for example, it is not surprisingly that "physical safety" relates to organised crime, violence and natural risks. Some risk factors are connected to more than one core value and give us an understanding of perceived values explaining the interrelation between them. For example "social stability" is related to three risk categories: violence, discrimination and immigration. These categories are also related to other core values: "territorial integrity," "physical safety" or "cultural integrity" explaining in this way the relationships between these core values. Such a table can help decision-makers and political actors to guide their activities to increase the sense of security and the level of security. 


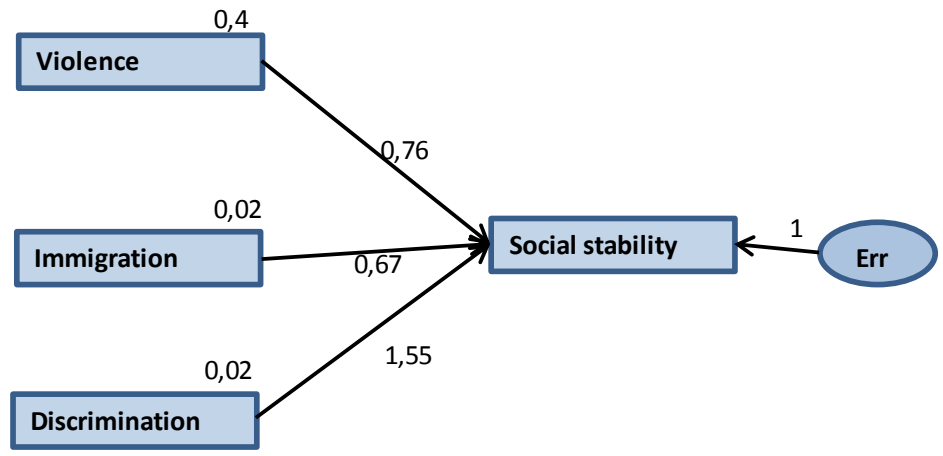

$P=0,98$

Figure 7: SEM: FCA for "social security."

Note: The numbers on the arrows represent the weights of explaining variables and the numbers over the symbols show their variances. The value of the Chi-Square statistic determines the probability level that this model describes the real situation.

Table 7. Risk categories related to the core values, as results of LR and CFA.

\begin{tabular}{|c|c|c|c|c|c|c|c|c|}
\hline & 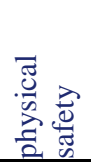 & 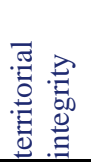 & 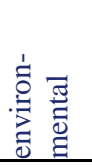 & 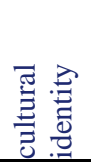 & 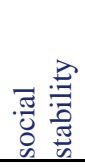 & 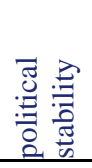 & 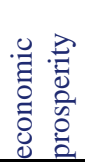 & 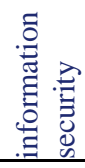 \\
\hline Political/ religious conflicts & & $\mathbf{x}$ & & & & $\mathbf{x}$ & & \\
\hline Corruption & & & & & & $\mathbf{X}$ & $\mathbf{x}$ & \\
\hline Organized crime, Terrorism & $\mathbf{x}$ & & & & & & & \\
\hline Violence & $\mathbf{x}$ & & & $\mathbf{X}$ & $\mathbf{x}$ & & & \\
\hline Economic recession & & & & & & & $\mathbf{x}$ & \\
\hline Discrimination & & & & $\mathbf{x}$ & $\mathbf{x}$ & & & \\
\hline Global risks & & & $\mathbf{x}$ & & & & & \\
\hline Natural risks & $\mathbf{x}$ & & $\mathbf{x}$ & & & & & \\
\hline Technical risks, Data security & & & & & & & & $\mathbf{x}$ \\
\hline Immigration & & $\mathbf{x}$ & & & $\mathbf{x}$ & & & \\
\hline Border security & & $\mathbf{x}$ & & & & & & \\
\hline
\end{tabular}




\section{Relations between the dimensions of security perception}

The investigation of correlations between core values enables a deeper understanding of the interplay of security values, and the way they are perceived.

Therefore we want to find out how the core values were assessed; were they alone or together with other core values in a report. Table 8 shows that assessments of just one core value were found in $38 \%$ of cases. In $56 \%$ of the cases, several core values were perceived together.

Table 8: Number of assessments with information on the combined assessment with other core values.

\begin{tabular}{|c|c|c|c|c|c|c|c|}
\hline \multicolumn{8}{|c|}{ Number of values assessed } \\
\hline \multirow[t]{2}{*}{ Assessed } & \multicolumn{5}{|c|}{ Country } & \multirow[t]{2}{*}{ Total } & \multirow[t]{2}{*}{$\%$} \\
\hline & Netherlands & Poland & Serbia & Spain & UK & & \\
\hline 0 & 83 & 9 & 0 & 2 & 1 & 95 & $5,2 \%$ \\
\hline 1 & 176 & 58 & 104 & 212 & 154 & 704 & $38,5 \%$ \\
\hline 2 & 141 & 50 & 148 & 57 & 151 & 547 & $29,9 \%$ \\
\hline 3 & 66 & 26 & 50 & 28 & 66 & 236 & $12,9 \%$ \\
\hline 4 & 37 & 18 & 20 & 10 & 27 & 112 & $6,1 \%$ \\
\hline 5 & 24 & 20 & 6 & 3 & 17 & 70 & $3,8 \%$ \\
\hline 6 & 5 & 10 & 5 & 3 & 9 & 32 & $1,7 \%$ \\
\hline 7 & 5 & 5 & 3 & 1 & 4 & 18 & $1,0 \%$ \\
\hline 8 & 2 & 5 & 0 & 7 & 1 & 15 & $0,8 \%$ \\
\hline Total & 539 & 201 & 336 & 323 & 430 & 1829 & $100,0 \%$ \\
\hline
\end{tabular}

For the nominal scaled variables (like country) the association between variables is measured with the contingency coefficient $C .{ }^{14}$ In our case the value $C(C=0,411)$ is relatively large and was highly significant, meaning that there are differences among countries in the way the core value are assessed. For example, in $65.5 \%$ of reports from Spain only one core value was assessed and, in contrast, in $66.6 \%$ of the reports from Poland, more core values were assessed in the same report.

The associations between the core variables were investigated with the "Odd Ratio independence test" (OR) and Spearman correlation coefficient, at a significance level $\mathrm{p}<0,0005$. A value close to 1 of OR shows no association between variables, a value smaller than 1 shows a negative association, and a value higher than 1 shows that the two core values were similarly assessed.

The interpretation of correlation strength is not unique in the literature. Most assessments define a value below 0,3 as weak, between 0,3 and 0,5 as moderate, and those 
Table 9. Odds ratios and correlations between core values.

\begin{tabular}{|c|c|c|c|c|c|}
\hline Variable 1 & Variable 2 & OR & $\begin{array}{c}\text { Common } \\
\text { assessed }\end{array}$ & Common assessed & $\begin{array}{c}\text { Spearman } \\
\text { correlation }\end{array}$ \\
\hline $\begin{array}{l}\text { Territorial } \\
\text { integrity }\end{array}$ & $\begin{array}{l}\text { Political } \\
\text { stability }\end{array}$ & 4,95 & 156 & $\begin{array}{l}52 \% \text { from var. } 2 \\
32 \% \text { from var. } 1\end{array}$ & 0,298 \\
\hline $\begin{array}{l}\text { Environmental } \\
\text { security }\end{array}$ & $\begin{array}{l}\text { Economic } \\
\text { prosperity }\end{array}$ & 7,14 & 222 & $\begin{array}{l}75 \% \text { from var. } 1 \\
33 \% \text { from var. } 2\end{array}$ & 0,345 \\
\hline $\begin{array}{l}\text { Political } \\
\text { stability }\end{array}$ & $\begin{array}{l}\text { Cultural } \\
\text { identity }\end{array}$ & 4,73 & 61 & $\begin{array}{l}44 \% \text { from var. } 2 \\
21 \% \text { from var. } 1\end{array}$ & 0,214 \\
\hline $\begin{array}{l}\text { Social } \\
\text { stability }\end{array}$ & $\begin{array}{l}\text { Cultural } \\
\text { identity }\end{array}$ & 4,98 & 84 & $\begin{array}{l}60 \% \text { from var. } 2 \\
18 \% \text { from var. } 1\end{array}$ & 0,225 \\
\hline $\begin{array}{l}\text { Political } \\
\text { stability }\end{array}$ & Social stability & 3,8 & 151 & $\begin{array}{l}50 \% \text { from var. } 1 \\
32 \% \text { from var. } 2\end{array}$ & 0,248 \\
\hline $\begin{array}{l}\text { Physical } \\
\text { safety }\end{array}$ & $\begin{array}{l}\text { Information } \\
\text { security }\end{array}$ & 0,39 & 133 & $\begin{array}{l}42 \% \text { from var. } 2 \\
12 \% \text { from var. } 1\end{array}$ & $-0,175$ \\
\hline
\end{tabular}

above 0,5 - as strong. Thus, we have only one moderate correlation from the total sample: those between "economic prosperity" and "environmental security." The negative correlation between "physical safety" and "information security" can be explained taking into account that these two dimensions were quite often assessed alone (see Table 10). Additionally, the meanings of the two core values are so different that a report dealing at the same time with both of them is rather improbable. The "cultural identity" is seldom a point of discussion: it was assessed in 53 of cases and in only five cases mentioned on its own. This means that in 48 cases this dimension is accompanied by another dimension of security.

Table 10. Number of reports in which each core value was assessed and reports where the core value was the only value assessed.

\begin{tabular}{lccc}
\hline Core values & $\begin{array}{c}\text { \# variable } \\
\text { assessed }\end{array}$ & \# assessed alone & \% assessed alone \\
\hline Physical safety & 915 & 399 & $43,6 \%$ \\
\hline Territorial integrity & 277 & 54 & $19,5 \%$ \\
Environmental sec & 140 & 16 & $11,4 \%$ \\
Cultural identity & 53 & 5 & $9,4 \%$ \\
\hline Social stability & 232 & 31 & $13,4 \%$ \\
\hline Political stability & 147 & 17 & $11,6 \%$ \\
\hline Economic prosperity & 392 & 99 & $25,3 \%$ \\
\hline Information security & 230 & 76 & $33,0 \%$ \\
\hline
\end{tabular}


The investigation of correlations for each country sample provided some new moderate correlations, and two strong correlations: "political stability" with "social stability" for Spain and "economic prosperity" with "environmental security" for Poland. Table 11 presents the most significant correlations ( $\mathrm{p}<0,0005)$.

1. The axis of correlation ("economic prosperity" - "environmental security") seems to be important in all countries, except Serbia.

2. A second axis of correlation involves "political stability," "territorial integrity," "social security," or "cultural identity." A combination of these values defines this axis, making it take various manifestations according to the special situation, for example:

- "Political stability" is often correlated with "territorial integrity" for Serbia and Poland, meaning that territorial concerns are politically relevant in these countries.

- "Political stability" is correlated with "social stability" for Spain, which means that social instabilities affect deeply political issues and vice versa.

The existence of the two axes of correlation means, however, that if concerns are displayed on more dimensions in the same report or same perception time, then they appear with preference in these combinations.

On the basis of these correlations we wanted to know if there could be some basic values (unobserved latent variables), which could promote the combined perceptions of more security values.

Structural Equation Modelling (SEM) of AMOS-tool can handle relationships between latent variables of observed data for a large sample size and provides a graphical image of the model (see Figure 8). Some details of the SEM-AMOS tool of IBM are presented in the appendix.

Table 11. Significant Spearman correlations between core values for each country.

\begin{tabular}{lcccc}
\hline $\begin{array}{l}\text { Spearman } \\
\text { Correlation }\end{array}$ & $\begin{array}{c}\text { Environmental vs } \\
\text { Economic }\end{array}$ & $\begin{array}{c}\text { Territorial vs } \\
\text { Political }\end{array}$ & $\begin{array}{c}\text { Political } \\
\text { vs Social }\end{array}$ & $\begin{array}{c}\text { Physical vs } \\
\text { Information }\end{array}$ \\
\hline Netherlands & $\mathbf{0 , 3 4 7}$ & $\mathbf{0 , 1 4 1}$ & $\mathbf{0 , 1 9 3}$ & $\mathbf{- 0 , 1 2 6}$ \\
United Kingdom & 0,402 & $\mathbf{0 , 2 6 8}$ & $\mathbf{0 , 1 9 7}$ & $\mathbf{- 0 , 2 5 2}$ \\
Serbia & $\mathbf{0 , 1 5 2}$ & 0,414 & $\mathbf{0 , 1 0 3}$ & $\mathbf{- 0 , 3 5 7}$ \\
Spain & $\mathbf{0 , 3 1 7}$ & $\mathbf{0 , 2 7 0}$ & 0,550 & $\mathbf{- 0 , 1 2 9}$ \\
Poland & 0,510 & 0,430 & $\mathbf{0 , 2 9 5}$ & $\mathbf{0 , 0 4 8}$ \\
\hline
\end{tabular}




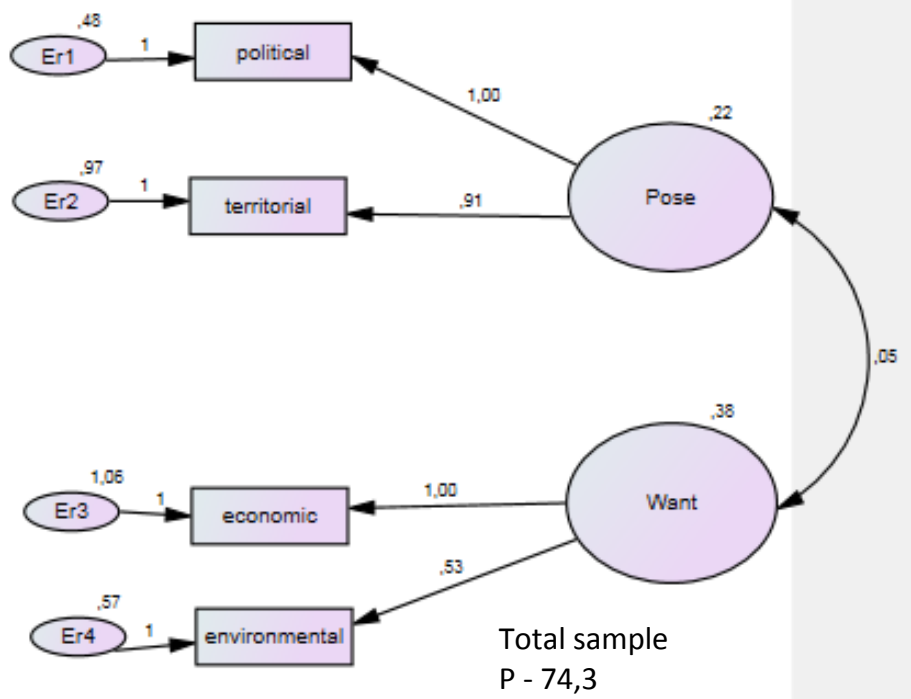

Figure 8: Graphical modelling with SEM (whole data).

Note: Squared symbols indicate measured variables and elliptical symbols indicate latent variables. The numbers on the arrows represent the weights of explaining variables and the numbers over the symbols show their variances.

The value of the Chi-Square statistic determines the probability level that this model could be the real one.

We make the hypothesis that the two core values ("political stability" - "social security" or "territorial integrity") are perceived as related to a latent variable, which was not directly measured. The second hypothesis is that the correlation "economic prosperity" - "environmental security" is also related to another latent variable. The two latent variables were named: Poise (free from instability) and Want (free from want). The power of the model is relatively high with $\mathrm{p}=0,743$, which means that the developed model could be a real one with the probability of $74 \%$. Details about the parameters that describe the goodness of fit are given in the appendix.

Assuming heterogeneity of data, we can expect stronger correlation behaviour within each country (see Table 11). We repeated the modelling for each country sample. The obtained images are similar to those for the total sample analysis (see Figure 9 in the Appendix).

We found out that the important clusters relate to "physical safety" or "economic prosperity" or to the rest (political, social, cultural, and territorial). 
The analysis of associations and interdependencies between the dimensions of perceived security indicates the existence of two bases for associations:

1. Freedom from want as specified by "economic prosperity" and "environment security"

2. Freedom from instability as supported by "political stability," "social security," and "territorial integrity."

In all samples a dominant assessment of "physical security" was observed, which was often the only security aspect discussed. That gives us the reason to consider the third matter of interest, namely freedom from fear.

\section{Conclusion}

Data on security perceptions from five European countries were available for this work. The aim was to identify factors influencing security perceptions and to understand the differences between countries. The eight core values display different aspects of the security perceptions. It is not surprising that "physical safety" is the most salient (identified in $50 \%$ of the cases) value as it directly affects our very existence. The "economic prosperity" is the second important dimension, which is particularly expressed in parliamentary and governmental reports as well as in reports from the private sector. Moreover, for the private sector the "economic prosperity" is the most important aspect, followed by "information security" and "physical security." In contrast, "cultural identity" was only assessed as "Main Topic" in just $3 \%$ of the cases.

Comparison of core values assessments between countries shows no big discrepancies, indicating a kind of homogeneity in the perception of security values in different regions of Europe.

The national political level was the dominant level of discussions for all the countries and sources. The local political level manifests in countries where territorial, political and social instabilities exist, like Serbia and Poland.

The perceptions of actors show also similarities between countries. One difference is that for Spain, Serbia and Poland the perception of national government being a victim (Object) is low (below $5 \%$ ), compared to UK and NL (38\% and $12 \%$ respectively). The distribution of roles reflects the responsibilities the actors have: the role AAA (Addressor, Addressee, or Affected) is clearly attributed to the Government and Parliament and the role "Object" (victim) - mostly to the "General public." "Civil society" and "Private sector" can play a bivalent role, having both an active role but also being a target of threats. A difference is that in Spain, Serbia and Poland 
the perception of "General public" as an actor is higher (over $78 \%$ ) compared to the UK and NL (60\% and $47 \%)$.

As related to the risk categories, it seems that in the North-Western region the primary discussion is on challenges that manifest at the European and global level like terrorism, global risks, immigration, cybersecurity and economic aspects, and that their impact/intensity is relatively low. In contrast, the Eastern Region (Serbia, Poland) are reflecting upon imminent political and territorial dangers at their borders or in their neighbouring countries and also upon their own social, economic and cultural problems.

The prioritisation of security dimensions was provided with the Security Perception Matrix (SPM). It confirms that "physical safety" is the critical value in all the countries, followed by "economic prosperity." Again, a similarity in the evaluation was established between the UK and the NL, which were critical only in "physical safety," and between Spain and Serbia, which had critical values for almost all dimensions except "cultural identity." Poland shows a mixed image where "physical safety" and "territorial integrity" are to be improved. The cautious study of the context factors (including risks, challenges) is the key for such an attempt.

The examination of correlations between core values showed that some core values such as "political stability," "social security," "territorial integrity," and "cultural identity" were mostly assessed in combination with each other. The other three values ("physical safety," "cyber security" and "economic prosperity") were partly unique subjects of discussion. Based on the weak to moderate linkages between core values, the SEM modelling showed similar images of the core interrelations in all countries. Consequently, three basic principles for the perception of security in Europe were asserted:

- freedom from want (linked to economic and environmental aspects);

- freedom from instability (linked to political, social and territorial aspects); and

- freedom from fear (linked to physical safety).

The last one seems to be the most critical at the moment.

The variability between countries bears on the manifestation of the second principle of "freedom from instability." Depending on context, dimensions like political, social, territorial, cultural and even economic can be more or less salient. The desire of stability relates to the humanitarian need for harmony, dignity, and respect in social and political context. 
The constant manifestation of the last principle of "freedom from fear," expressed through "physical safety" and "information security," is a characteristic of the current European security perception. Both dimensions relate to primary needs of human beings: not to be physically and privately attacked, destroyed or offended. Further research is necessary in order to provide consistency of current finding and observe the development of security perception in Europe.

\section{Appendix: Statistical analysis of data with SEM}

The descriptive tools and contingency tables enabled the comparisons between different countries and sources. The relationships between variables were analysed with the Factor-Analysis (FA) tool and Linear Regression (LR) with the statistical tool SPSS. ${ }^{15}$ FA and LR generally require the assumption of a normal distribution of variables. Our variables have primarily ordinal scale, but FA and LR allow to some extent ordinal variables with numerical coding, especially when the sample size is large enough. In addition, FA and LR were applied as preliminary investigation in order to obtain a proposal model to be confirmed by the Conformational Factor Analysis (CFA) with SEM. The modelling of different core-values was accomplished using the "Structured Equation Modelling"" (SEM) with the IBM-AMOS tool. ${ }^{17}$ The term "structured equation" refers to the core concept of SEM handling relationship between latent variables. SEM is very flexible, being able to handle a system of regression equations. The main feature of SEM is to compare the proposed model with empirical data. Not only latent variables can be modelled with SEM, also measured variables can be fitted depending on other (independent) variables. In this case the tool AMOS provides a confirmatory factor analysis (CFA). The price to be paid for SEM in order to obtain a good fit consists of the large sample sizes needed and the fact that SEM is often seen as complicated and difficult to understand. Preacher provides more information on the SEM-AMOS tool. ${ }^{18}$

\section{Evaluating the Fit of SEM models}

A model is said to fit the observed data if the model covariance matrix is equivalent to empirical covariance matrix. Our data are ordinal and therefore we used the estimation method "asymptotically distribution free" (ADF) which is recommended for these cases. ADF produces in general an accurate $\chi^{2}$ test statistic and standard errors if the sample size is sufficiently large $(>2000) .{ }^{19}$ The $\chi^{2}$ test statistic is used for hypothesis testing. It was used to test the null hypothesis that the difference between the two covariance matrices is zero. If the $\mathrm{p}$-value associated with $\chi^{2}$ is larger than 0,05 the null hypothesis is accepted and the model is compatible with the empirical covariance matrix. It is still uncertain if other models may fit the data equally well or better. Therefore, a number of Measure of Fit (MoF) parameters are always recommended for the evaluation of results. 
The value obtained for modelling our whole data $\mathrm{p}=0,74$ gives the probability that this model represents the empirical data, and in this case it is a good fit. ${ }^{20} \chi^{2}$ test statistic is the only one which has an associated significance test.

The other statistical evaluations are descriptive and are classified in three classes: measures of overall fit, measure based on model comparisons, and measures of model parsimony. These descriptive "Goodness of Fit" measures were developed as alternatives to $\chi^{2}$ when dealing with small sample sizes. Some of these fit parameters are briefly presented below.

RMSEA (Root Mean square Error of Approximation) is a measure of discrepancy between the covariance matrices and indicates an approximately good fit if its value is less than or equal to 0,05 . A confidence interval is also reported. In our case the CI is $(0,0-0,043)$, which shows a very good fit.

RMR (Root Mean Square Residual) is based in fitted residuals, which express the remaining discrepancies between the covariance matrices. The value of 0,002 in this case indicates a very good fit.

NFI (Normed Fit Index), GFI (Goodness-Of Fit Index) and RFI (Relative Fit Index) are measures based on model comparisons with the saturated model and the independence model. A value close to one indicates a good fit. We got NFI =0,999, $\mathrm{GFI}=1$ and $\mathrm{RFI}=1$, which indicate a good fit again.

Parsimony is also important to assess whether we have to compare alternative models. A measure of parsimony is AIC (Akaike Information Criterion) and ECVI (Expected Cross Validation Index). Indication of the good fit is when AIC or ECVI (default model) < AIC or ECVI (saturated model), which is the case for our data set.

\section{Fit parameters for all countries}

The fit-parameters are given in Table 12 in the column "Total sample." The analysis shows that the model is adequate for the description of relationships. However, the covariance comparison of the model with empirical data shows a significance level of only $11 \%$. A much larger sample size would be necessary to attend the real significance with $\chi^{2}$ test. Another reason could be the heterogeneity of the data. The obtained images for each country are similar to those for the total sample analysis.

The "economic prosperity" linked to "environmental security" or to other dimensions builds one important cluster. The data from the UK, the NL, Spain and Poland shows that "political security" and "social security" are strongly correlated and together with "cultural identity" build the second important cluster. This second cluster takes different forms for different countries. 
Table 12: Goodness of Fit Parameters for the whole sample and for each country sample.

\begin{tabular}{|c|c|c|c|c|c|c|}
\hline & $\begin{array}{c}\text { Total } \\
\text { sample }\end{array}$ & NL & UK & Spain & Serbia & Poland \\
\hline Probability $\chi^{2}$ & 0,743 & 0,504 & 0,978 & 0,595 & 0,803 & 0,978 \\
\hline RM SEA CI & $0-0,043$ & $0-0,999$ & $0-0$ & $0-0,066$ & $0-0,0508$ & $0-0$ \\
\hline$R M R$ & 0,002 & 0,005 & 0,003 & 0,041 & 0,019 & 0,009 \\
\hline$N F I$ & 0,999 & 0,986 & 0,999 & 0,982 & 0,983 & 0,991 \\
\hline$R F I$ & 0,994 & 0,913 & 0,998 & 0,964 & 0,944 & 0,977 \\
\hline$G F I$ & 1 & 0,999 & 1 & 0,998 & 0,999 & 0,998 \\
\hline$A I C$ & $<$ & $<$ & $<$ & $<$ & $<$ & $<$ \\
\hline$E C V I$ & $<$ & $<$ & $<$ & $<$ & $<$ & $<$ \\
\hline $\begin{array}{l}\text { Parameter significance } \\
\text { level }\end{array}$ & 0,086 & $<0,05$ & 0,12 & $<0,05$ & 0,08 & $<0,05$ \\
\hline Covariance reproduction & 0,117 & $<0,05$ & $<0,099$ & 0,243 & 0,08 & 0,119 \\
\hline Sample size & 1829 & 539 & 430 & 323 & 336 & 201 \\
\hline
\end{tabular}

The "physical safety" is sometimes negatively correlated with "economic prosperity" getting to a polarised "Want-Fear" cluster for the UK, Serbia and Spain. Sometimes this correlation is not strong enough and this variable is not taken into the modelling because a variable alone cannot build a cluster. This is the case for the NL and Poland. The same is true for "information security," which is only negatively weakly correlated with "physical safety."
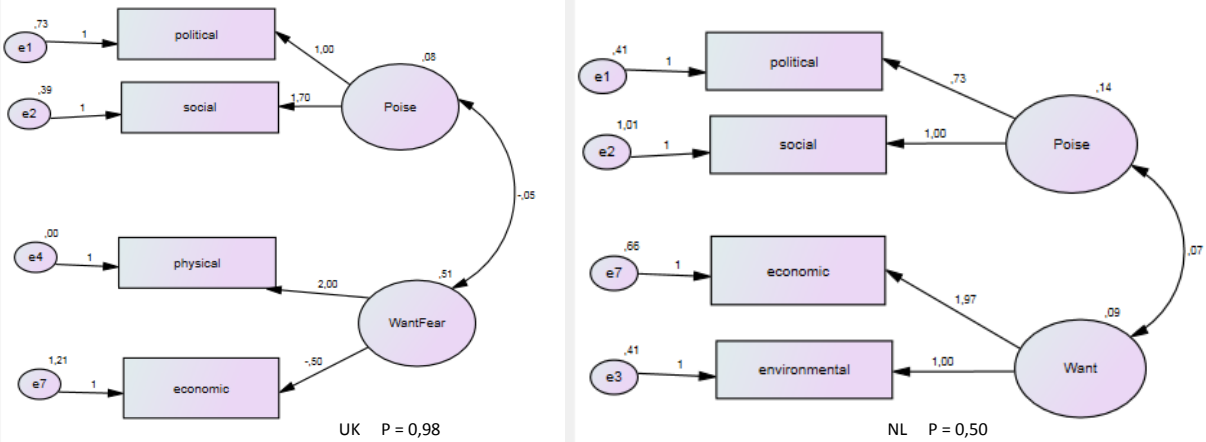

Figure 9.a: SEM Model for the UK and for the Netherlands. 

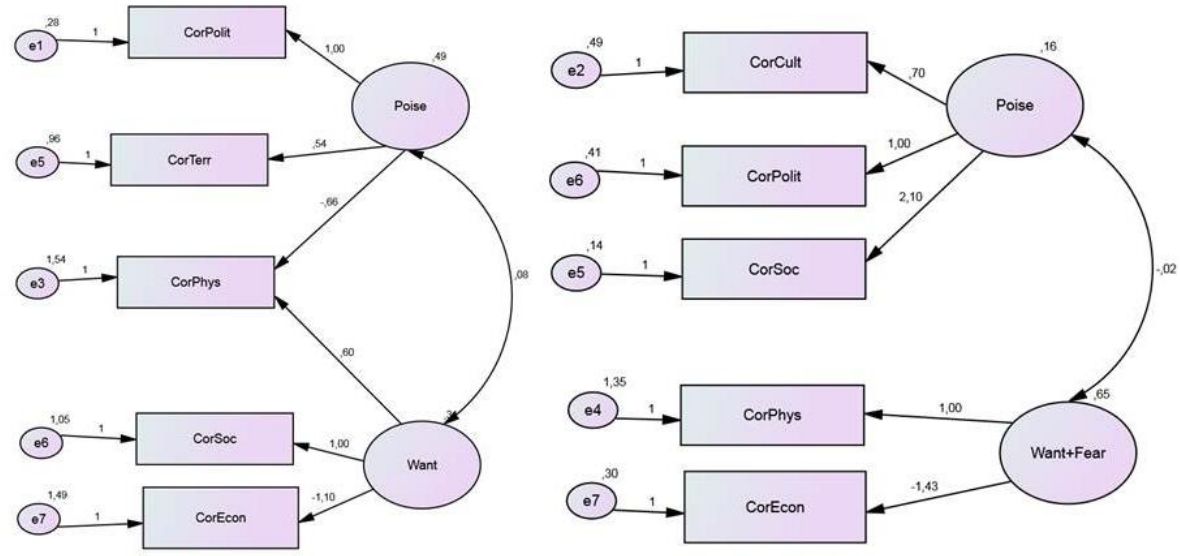

Serbia $P=0,80$

Spain $P=0,59$

Figure 9.b: SEM Model for Serbia and Spain.

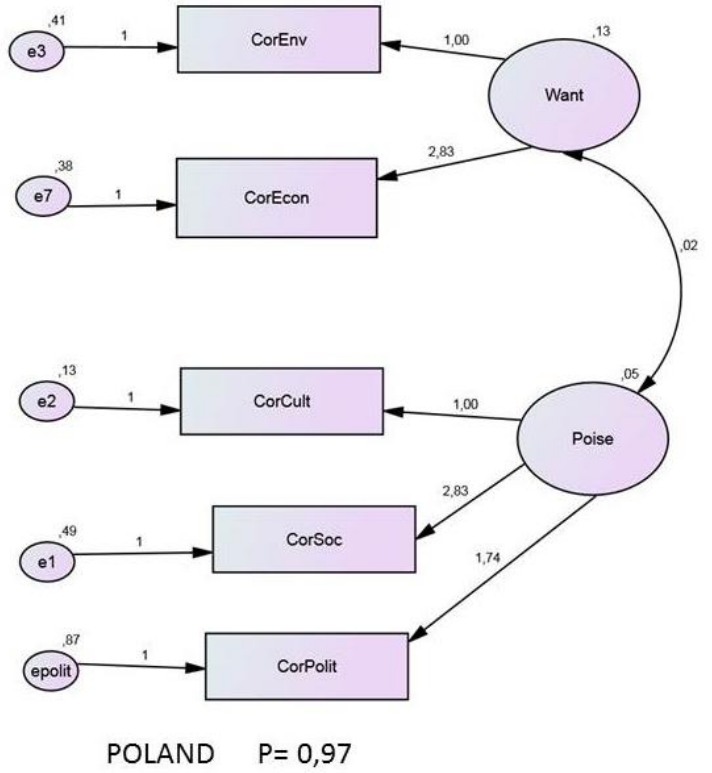

Figure 9.c: SEM Model for Poland. 


\section{Acknowledgement}

The research leading to these results has received funding from the European Community's Seventh Framework Programme (FP7/2007-2013) under Grant Agreement $\mathrm{n}^{\circ} 605142$. We thank the EvoCS project partners contributing to the discussions on the described work. Only the authors' views are reflected, the Commission and the Project are not liable for any use that may be made of the information contained therein.

\section{Notes:}

${ }^{1}$ UN Secretary General, "In larger Freedom: Towards Development, Security and Human Rights for All," September 2005, available at http://www.un.org/en/events/pastevents/ in_larger_freedom.shtml; United Nations Development Program, Human Development Report 1994 (New York: Oxford University Press, 1994), available at http://hdr.undp.org/ sites/default/files/reports/255/hdr_1994_en_complete_nostats.pdf.

2 Hans Günter Brauch is lecturer and visiting professor with a focus on German foreign policy, European integration, international environmental policy, foreign and security policy, defence and arms control policy of industrialized countries.

${ }^{3}$ Report on Cultural Issues: Changing Perception of Security and Interventions, Deliverable 4.4, CPSI Consortium (n.d.), available at http://www.esci.at/eusipo/CPSI-WP4_4-Cultural_ Issues.pdf; Securipedia, http://securipedia.eu/mediawiki/index.php/Security_culture.

${ }^{4}$ Security culture is the concept dealing with the way security is perceived by people and the explanation thereof.

5 Hans Günter Brauch et al., eds., "Concepts of Security Threats, Challenges, Vulnerabilities and Risk," in Coping with Global Environmental Change, Disasters and Security, Hexagon Series on Human and Environmental Security and Peace 5 (Berlin and Heidelberg: Springer, 2011), http://dx.doi.org/10.1007/978-3-642-17776-7_2.

${ }^{6}$ Fabien Nathan is member of the European Network of Excellence "Global Monitoring for Security and Stability" (GMOSS) within the Peace Research and European Security Studies (AFES-PRESS) research group in Mosbach (Germany).

7 See also UN Development Programme, HDR Office, available at http://hdr.undp.org/sites/ default/files/human_security_guidance_note_r-nhdrs.pdf.

${ }^{8}$ Fabien Nathan, "Natural Disasters, Vulnerability and Human Security," in Facing Global Environmental Change, edited by eds. Hans Günter Brauch et al., Hexagon Series on Human and Environmental Security and Peace 4 (Berlin and Heidelberg: Springer, 2009), 1121-29, http://dx.doi.org/10.1007/978-3-540-68488-6_87.

9 EvoCS Website, http://evocs-project.eu/content/project-objectives.

${ }^{10}$ Mindaugas Norkevičius, Maria Radziejowska, Anna Sara Ligeti, Marcin Terlikowski and Peter Tanchak, Case Study on the Eastern EU Border, Deliverable 6.2, EvoCS Consortium, 2015, available at http://dx.doi.org/10.11610/evocs.d62.

${ }^{11}$ Milos Jovanovic, Valeri Ratchev, Todor Tagarev, Vesselin Petkov, Antonia Todorova and Pinar Elman, Case Study on South-Eastern Europe, Deliverable 8.2, EvoCS Consortium, 2015, available at http://dx.doi.org/10.11610/evocs.d82.

${ }^{12}$ Paola Sartori, Alessandro Marrone, Daniele Fattibene, Antonia Bierwirth, Lee Bosher, Ksenia Chmutina, Andrew Dainty, Federica Di Camillo, Paola Tessari, Alessandro Riccardo 
Ungaro, Case Study on West Mediterranean Europe, Deliverable 5.2, EvoCS Consortium, 2015, available at http://dx.doi.org/10.11610/evocs.d52.

${ }^{13}$ Ksenia Chmutina, Lee Bosher, Andrew Dainty, Tim Sweijs, Jacques Mukena, Erik Frinking, Barbara Lucini, and Marco Lombardi, Case study on North-West Europe, Deliverable 7.2, EvoCS Consortium, June 2015, available at http://dx.doi.org/10.11610/evocs.d72.

${ }^{14}$ The contingency coefficient is calculated directly from the test variable $\chi^{2}$ and the total sample size $\mathrm{n}$.

${ }^{15}$ SPSS Tutorials, http://www.spss-tutorials.com/tools/.

${ }^{16}$ Structural Equation Modeling, Dell Statistics Textbook, available at http://documents.software.dell.com/Statistics/Textbook/Structural-Equation-Modeling.

${ }^{17}$ SPSS Amos, IBM, available www-03.ibm.com/software/products/de/spss-amos.

${ }^{18}$ Kristopher Preacher, "Quantifying Parsimony in Structural Equation Modeling," Multivariate Behavioural Research 41, no.3 (2006), http://dx.doi.org/10.1207/s15327906mbr4103_1.

${ }^{19}$ UN Development Programme; Nathan, "Natural Disasters, Vulnerability and Human Security."

${ }^{20}$ Psychlopedia, Quantitative Data Analysis, Structural Equation Modeling, available at http://www.psych-it.com.au/Psychlopedia/article.asp?id=277.

Daniela LIEBERZ is a scientific employee at Fraunhofer Institute for Technology Trend Analysis (Fraunhofer INT). She studied physics and obtained a doctoral degree in Nuclear Physics at the Institute for Nuclear Physics in Cologne, Germany. Ms. Lieberz provided a set of publications related to theoretical modelling of excited Xenon and Barium nuclei. Later on, she received an additional qualification in applied statistics in Heidelberg, working in the medical and clinical studies area. She has also practical experience in actuarial activities in the field of industrial insurances. At present, she is working in international research and technology management, with research interest strongly related to data modelling and data analytics. E-mail: daniela.lieberz@int.fraunhofer.de. 